Research Paper:

\title{
The Relationship Between Knowledge About Coronary Heart Diseases Risk Factors and Health-promoting Lifestyle
}

\author{
Marhamat Farahaninia' $^{1} \odot$, Sakineh Tarvirdinasab ${ }^{2^{*}} \odot$, Zahra Ahmadi $^{1} \odot$ Mahboobeh Rasouli $^{3}$
}

1. Nursing Care Research center, School of Nursing and Midwifery, Iran University of Medical Sciences, Tehran, Iran.

2. Department of Community Health Nursing, School of Nursing and Midwifery, Iran University of Medical Sciences, Tehran, Iran

3. Department of Biostatistics, School of Public Health, Iran University of Medical Sciences, Tehran, Iran.

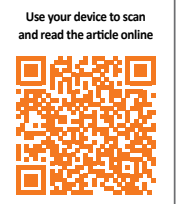

ditation: Farahaninia1, M., et al., 2019. The Relationship Between Knowledge About Coronary Heart Diseases Risk Factors and Health-promoting Lifestyle. Journal of Client-Centered Nursing Care, 5(1), pp. 43-52. http://dx.doi.org/10.32598/ jecnc.5.1.43

http://dx.doi.org/10.32598/jccnc.5.1.43

(A) 0

Article info:

Received: 08 Aug 2018

Accepted: 23 Dec 2018

Published: 01 Feb 2019

\section{A B S TRACT}

Background: Patients with coronary heart diseases need knowledge about the risk factors of the disease to manage their illness. This study aimed to investigate the relationship between knowledge about coronary heart diseases risk factors and health-promoting lifestyle in adults living in Tabriz City.

Methods: This descriptive correlational study was conducted on 346 adults older than 18 years old that were selected by convenience sampling method from public places in Tabriz. The study data were collected by a demographic characteristics form, Heart Disease Fact Questionnaire (HDFQ) and Health Promoting Lifestyle Profile (HPLP) and analyzed by analysis of variance, Independent t-test, Pearson correlation coefficient and linear regression analysis using SPSS-PC v. 22.

Results: The results showed that the knowledge of $57.51 \%$ of the participants was good. The mean \pm SD score of health promoting lifestyle was $136.30 \pm 21.15$ (in moderate level). Spiritual growth dimension $(M=26.8)$ and exercise and physical activity dimension $(M=16.54)$ had the highest and lowest mean scores, respectively. The results also showed that there is a significant relationship between knowledge of coronary heart diseases risk factors and health promoting lifestyle $(\mathrm{p}<0.001$ ). There was a significant relationship between the knowledge of coronary heart disease risk factors with age, marital status, occupational status, economic status, history of diabetes and lipid profile $(\mathrm{p}<0.05)$; but health promoting lifestyle was only associated with history of diabetes $(\mathrm{p}=0.03)$.

Conclusion: According to the findings, performing educational interventions at different levels of prevention could increase the knowledge of these patients about the risk factors of coronary heart disease and hopefully in promoting their lifestyle.

\section{* Corresponding Author:}

Sakineh Tarvirdinasab, MSc.

Address: Department of Community Health Nursing, School of Nursing and Midwifery, Iran University of Medical Sciences, Tehran, Iran Tel: +98 (914) 2059958

E-mail: farzanehnurse.2014@gmail.com 


\section{Highlights}

- Cardiovascular diseases are a significant public health issue that results in disability, mortality, and economic burden in most countries.

- Almost half of cardiovascular diseases are caused by coronary artery diseases.

- Modifiable risk factors of heart disease such as unhealthy diet, physical inactivity, smoking, and overweight have a high prevalence in the community.

- According to the World Health Organization, the greatest achievement of advanced societies in preventing many diseases, like coronary artery diseases is due to the awareness of people and control of risk factors.

\section{Plain Language Summary}

Health sciences that previously focused on the treatment of the diseases have now shifted to the prevention of diseases and promotion of health through lifestyle improvements. Health-promoting lifestyle will result in maintaining the function and independence of individuals, improving their quality of life, and reducing health care costs. This study aimed to examine the relationship between people's awareness of risk factors of coronary heart diseases and health-promoting lifestyle. The study findings showed that the spiritual growth had the highest and exercise and physical activity the lowest mean scores of health-promoting lifestyle dimensions. The importance of physical activity in the prevention of coronary artery disease should be emphasized in these courses.

\section{Background}

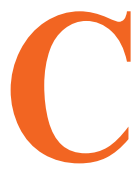

ardiovascular disease as a major public health issue in most countries leads to disability, mortality, and economic burden (Chiou, Hsu \& Hung, 2016). Cardiovascular diseases are a group of illnesses of heart and blood vessels, including coronary heart disease and cerebrovascular disease which may manifest as a stroke and transient ischemic attack. Coronary artery disease accounts for almost 50\% of cardiovascular diseases (Qidwai \& Ashfaq 2013). Each year, coronary heart disease cause 17.3 million deaths worldwide, and it is expected to reach 23.3 million by 2030 (Baldwin 2014). More than $25 \%$ of the deaths of people aged over 35 years in the United States are due to coronary heart disease (Chiou et al. 2016; Hughes et al. 2015). Previous research has identified coronary heart disease as the first and most common cause of death in Iran. The mortality rate of coronary heart disease in Iran is high; approximately 300 people die every day due to the complications of this disease (Forouzanfar et al. 2014; Mahmoodi et al. 2014; Mohammadian-Hafshejani et al. 2014).

There are significant gender differences with regard to the symptoms of coronary heart disease (Najafi et al. 2015). A significant effort to identify and prevent coro- nary heart disease is Framingham's Cohort study conducted by the Department of Public Health of the United States. The results of this study suggested that coronary heart disease does not accidentally occur in men, and high-risk individuals can be easily identified by their clinical symptoms. Potential risk factors which were identified in this study are male gender, old age, high serum lipids, hypertension, smoking, diabetes (or even mild degrees of glucose intolerance), obesity, low vital capacity, and certain disorders detectable by electrocardiography. The Framingham study also examined the effects of multiple risk factors; they concluded that individuals with a combination of risk factors are at higher risk for coronary heart disease (Dawber et al. 2015).

The modifiable risk factors of heart disease, such as an unhealthy diet, physical inactivity, smoking and alcohol consumption, and increased Body Mass Index (BMI) have are highly prevalent (Shaheen et al, 2015). However, the presence of one or more risk factors in an individual does not confirm coronary heart disease. Additionally, controlling a risk factor does not reflect the absence of coronary heart disease; however, controlling major risk factors can reduce the risk of coronary heart disease, its complications, and progression rate or symptoms frequency (Chiuve et al. 2008). Therefore, the importance of primary and secondary prevention of coronary heart disease and early detection of its associated risk factors are inevitable (Varbo et al. 2013). 
According to the World Health Organization (WHO), the greatest achievements of advanced societies in preventing many diseases, mainly coronary artery disease rooted in the awareness of people and control of risk factors (Baldwin 2014). Individuals' limited awareness on the related risk factors can lead to inappropriate health behaviors, inadequate adherence to therapeutic regimens, disease recurrence, and ultimately, increased hospitalization and high medical costs (Chiou et al. 2016); therefore, to prevent this problem, people's knowledge must be improved to promote their lifestyle (Chiou et al. 2016; Hughes et al. 2015).

Health-promoting lifestyle will lead to maintaining the function and independence of individuals, improving their quality of life, and reducing healthcare costs (Hajizadeh-Sharafabad \& Alizadeh 2016). Due to the high cost of healthcare, prevention approaches have been subsituted by treatment ones. In other words, health sciences that previously focused on the treatment of diseases have now concentrated on prevention and health through lifestyle improvements (Bhandari \& Kim 2016; Mohsenipoua et al. 2016). Recent medical treatments through blood lipids reduction and blood pressure treatment to reduce the incidence of coronary heart disease have been effective; however, a healthy lifestyle sill has a significant impact which has been highlighted (Åkesson et al. 2014).

Many scientific sources have categorized the healthpromoting lifestyle in 6 classes, including nutrition, physical activity, stress management, health responsibilities, interpersonal relationships, and spiritual growth. The WHO has also signified the importance of a healthpromoting lifestyle as a critical strategy for achieving an optimal quality of life (Chiou et al. 2016; Cho et al. 2014). By modifying lifestyle, early death due to coronary heart disease can be prevented. Changing the lifestyle from inactive to active, reduces the risk for coronary heart disease, up to 30\% (Capewell et al. 2009).

A total $47 \%$ of the deaths are due to coronary heart disease in Tabriz Province, due to its industrialization (Ghaffari et al. 2017). Considering the importance of achieving a health-promoting lifestyle and expanding knowledge in preventing coronary heart disease, studies have indicated that an increase in health promotion is associated with increased knowledge; however, others failed to endorse such a relationship (Carr et al. 2014; de Melo Ghisi et al. 2014; Johnson et al. 2015). The main group for studies about lifestyle and the knowledge on associated risk factors were coronary heart disease patients; not the general public or healthy people (Anderson et al. 2016). Moreover, public information is required for the primary prevention of coronary heart disease (Yusuf et al. 2015). Thus, the current research aimed to determine the relationship between knowledge about coronary heart disease risk factors and a healthpromoting lifestyle in adults of Tabriz City, Iran.

\section{Materials and Methods}

This was a descriptive correlational study. A total of 346 adults aged $>18$ years, able to read and write and without a history of the previous hospitalization due to heart disease were selected by convenience sampling method from public places (mosques, parks, shopping malls, Friday prayer) in Tabriz City, Iran.

Three questionnaires, including demographic characteristics, form, Heart Disease Fact Questionnaire (HDFQ), and Health Promotion Lifestyle Profile (HPLPHII) were used to collect data.

Demographic characteristics included age; gender; height; weight; educational level; occupational status; occupation type; marital status; histories of diabetes, hypertension, serum lipid, cardiovascular disease in the immediate family, as well as smoking and alcohol consumption.

HDFQ is a 25-item instrument that measures the knowledge on major risk factors for the development of coronary heart disease. Each item is responded by true (score: 1), false (score: 0), or I am not sure (score: 0) options. Total scale scores are calculated by summing the total number of correct answers and ranges from 0-25. Higher scores indicate a higher level of knowledge (Wagner et al. 2005).

HDFQ has been used in this research for the first time in Iran. For the present research, the authors obtained permission to use the original questionnaire. To translate the questionnaire, 3 translators (two translators in medical fields and one bilingual specialist) translated the text into Persian. Then, the translated text (by a bilingual specialist) was back-translated from Persian to English by two translators. The translated Persian and English texts were compared with the main text of the tool; necessary corrections were made to provide a better understanding for the study participants. For evaluating the qualitative content validity of the scale, the questionnaire was provided to 10 members of the Nursing and Midwifery faculty, and their corrective comments were applied. To determine the reliability of the questionnaire, a pilot study was conducted on 20 participants, and its test-retest reliability was calculated equal to 0.89 . In addition, to determine the internal consistency of HDFQ, the Kuder-Richardson 21 was used (Kuder-Richardson 21=0.78).

The HPLPHII consists of 52 questions and 6 subcategories, including nutrition, physical activity, health responsibility, stress management, interpersonal relationships, and spiritual growth. Each question is scored 
on a 4-point Likert-type scale (1: never, 2: sometimes, 3: often, and 4: routinely). The minimum and maximum obtainable scores of this questionnaire are 52 and 208. Higher scores indicate a positive health-promoting lifestyle, and lower scores demonstrate an adverse healthpromoting lifestyle (Walker et al. 1987).

The Validity and reliability of the Persian version of this tool have been calculated by Mohammad Zeidi and colleagues. The Cronbach's alpha coefficient for the total scale was calculated as 0.82, and for the subscale as 0.64-0.91 (Mohammadi Zeidi, Pakpour Hajiagha \& Mohammadi Zeidi, 2012). In this research, Cronbach's alpha coefficient for the total scale was equal to 0.91 and for the subscales was between 0.66 and 0.90 .

Data collected from 346 people were analyzed using SPSS. Descriptive statistics (frequency, percentage, mean, and standard deviation), and inferential statistics (Analysis of Variance [ANOVA]), Independent Samples t-test, Pearson's correlation coefficient, and linear regression analysis) were used for data analysis.

\section{Results}

In total, $57 \%$ of the subjects were female, and $43 \%$ were male. The Mean \pm SD age of the subjects was 39.01 \pm 12.17 years, and $72 \%$ were married. The mean score of healthpromoting lifestyle was 136.30 . Spiritual growth dimension (26.8) had the highest mean score; while exercise and physical activity dimensions (16.54) had the lowest mean score (Table 1).

Pearson's correlation coefficient results suggested a significant correlation between knowledge about coronary heart disease risk factors and health-promoting lifestyle $(\mathrm{P}<0.01)$; however, the correlation coefficient was low. Furthermore multiple regression models were used to control conflicting variables (e.g., age, occupation, and economic status); the relevant results indicated a significant relationship between knowledge about coronary heart disease risk factors and health-promoting lifestyle $(\mathrm{P}<0.001)$ (Table 2).

Pearson's correlation coefficient detected no significant relationship between the health-promoting lifestyle and BMI and age at the significance level of 0.05. Independent Samples t-test results revealed that women had had a higher score of a health-promoting lifestyle than men; however, there was no significant gender difference in health-promoting lifestyle score at the significant level of 0.05 . ANOVA results suggested no significant association between health-promoting lifestyle scores and material status, occupational status, occupation type, educational status, and economic status at the significance level of 0.05 .

Independent Samples t-test results indicated that the men with a history of diabetes achieved higher health-promoting lifestyle scores; there was a statistically significant difference between the health-promoting lifestyle score of individuals with and without a history of diabetes $(\mathrm{P}=0.030)$. Independent Samples t-test also revealed that the health promotion lifestyle score in people with a history of hypertension, high cholesterol, heart disease, cigarette smoking, and alcohol consumption was not significantly higher than those with no history of these diseases at the level of 0.05 (Table 3).

The results of multiple regression analysis indicated a significant relationship between knowledge on coronary heart disease risk factors and some demographic variables, including age, marital status, economic status and a history of high serum lipid (Table 4).

Table 1. Statistics of health-promoting lifestyle and its dimensions among the adults in Tabriz

\begin{tabular}{cccc}
\hline Dimensions of a Health-Promoting Lifestyle & Mean \pm SD & Range & Achievable Score \\
\hline Spiritual growth & $26.8 \pm 5.19$ & $10-36$ & $1-4$ \\
Health responsibility & $24.15 \pm 5.89$ & $9-36$ & $1-4$ \\
\hline Interpersonal relations & $25.44 \pm 5.20$ & $9-36$ & $1-4$ \\
Stress management & $19.16 \pm 4.28$ & $8-32$ & $1-4$ \\
\hline Exercise and physical activity & $16.54 \pm 5.55$ & $11-36$ & $1-4$ \\
\hline Nutrition & $24.22 \pm 4.70$ & $82-205$ & $52-208$ \\
\hline
\end{tabular}


Table 2. Correlation between knowledge of coronary heart disease risk factors and a health-promoting lifestyle

\begin{tabular}{|c|c|c|c|c|c|c|c|}
\hline \multirow{2}{*}{ Variable } & \multicolumn{2}{|c|}{ Unstandardized Coefficients } & \multirow{2}{*}{$\begin{array}{c}\text { Standardized } \\
\text { Coefficients } \\
\text { (Beta) }\end{array}$} & \multirow{2}{*}{$\mathbf{t}$} & \multirow{2}{*}{ Sig. } & \multicolumn{2}{|c|}{$\begin{array}{l}\text { Confidence Limit 95\% for } \\
\text { Regression Coefficients (B) }\end{array}$} \\
\hline & SD & Coefficient & & & & Upper Limit & Lower Limit \\
\hline $\begin{array}{l}\text { Constant } \\
\text { Coefficient }\end{array}$ & 139.85 & 9.82 & - & 14.25 & $P<0.001$ & 120.54 & 159.16 \\
\hline Age & 0.11 & 0.1 & 0.06 & 1.014 & 0.250 & -0.08 & 0.3 \\
\hline $\begin{array}{l}\text { Occupation Status } \\
\text { (Unemployed) }\end{array}$ & - & - & - & - & - & - & - \\
\hline $\begin{array}{l}\text { Occupation Stats } \\
\text { (Employee) }\end{array}$ & 2.2 & 2.99 & 0.05 & 0.74 & 0.460 & -3.68 & 8.09 \\
\hline $\begin{array}{l}\text { Occupation Type } \\
\text { (Housewife) }\end{array}$ & 0.22 & 2.65 & 0.01 & 0.08 & 0.930 & -5 & 5.44 \\
\hline Economic Status & -1.98 & 1.65 & -0.06 & -1.2 & 0.230 & -5.23 & 1.28 \\
\hline $\begin{array}{c}\text { Awareness of risk fac- } \\
\text { tors of coronary artery } \\
\text { disease }\end{array}$ & 0.83 & 0.26 & 0.18 & 3.17 & $P<0.0001$ & 0.31 & 1.34 \\
\hline
\end{tabular}

Client- Centered Nursing Care

\section{Discussion}

The current study aimed to investigate the relationship between knowledge about coronary heart disease risk factors and a health-promoting lifestyle in adults of Tabriz. The obtained results indicated that the knowledge of $57.51 \%$ of the study participants was at a good level. In a recent study, the knowledge of $82 \%$ of the participants was reported as good (Angosta \& Speck 2014). Some other studies have revealed similar results (Wagner et al. 2005; Baldwin 2014) .

Knowledge on coronary heart disease risk factors is beneficial for the people at risk to evaluate themselves and increase their motivation to raise their awareness in this aspect. Thus, knowledge and behaviors that reduce the risk for cardiovascular conditions is the priority for the future life of patients with coronary heart disease (Chinekesh et al. 2018).

In this study, the Mean \pm SD score of having a healthpromoting lifestyle was $136.30 \pm 21.15$. Spiritual growth dimension had the highest (26.8), and exercise and physical activity dimension had the lowest (16.54) mean scores. In a study, different domains of lifestyle and its relationship with cardiovascular risk factors were assessed in patients who had stenosis of vessels of $>50 \%$ and those who had the same stenosis of $\leq 50 \%$. In that study, "spiritual growth" and "interpersonal relationships" had the highest and "stress management" had the lowest mean score in the two groups (Pouy 2015). In other studies, the highest average score was related

Table 3. Relationship between a health-promoting lifestyle and demographic variables in adults of Tabriz

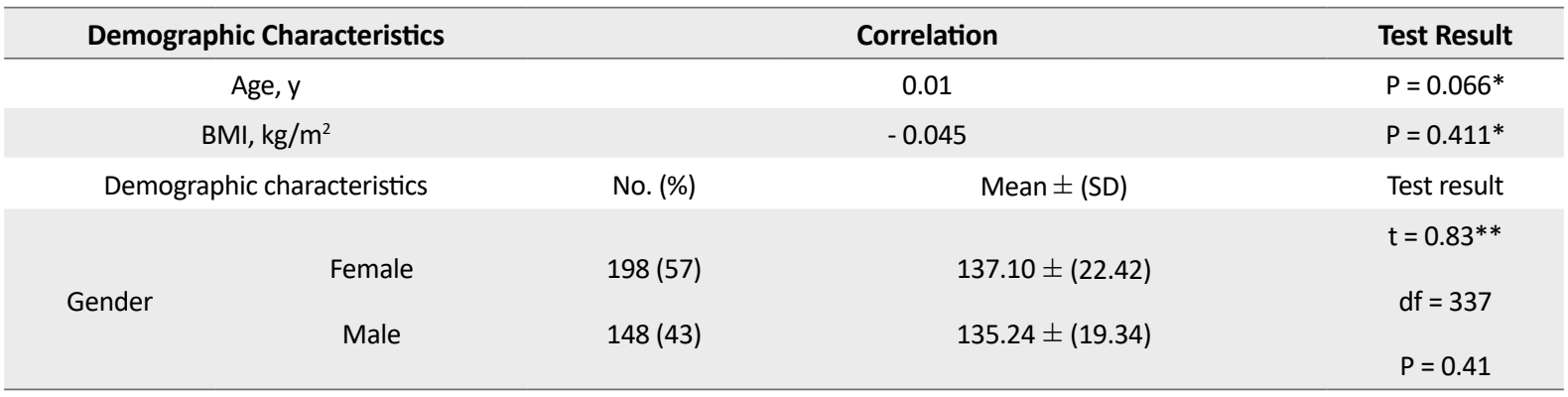




\begin{tabular}{|c|c|c|c|c|}
\hline \multicolumn{2}{|c|}{ Demographic Characteristics } & \multirow{2}{*}{\multicolumn{2}{|c|}{$\begin{array}{c}\text { Correlation } \\
137.19 \pm 21.60\end{array}$}} & \multirow[t]{2}{*}{ Test Result } \\
\hline \multirow{4}{*}{ Marital status } & single & & & \\
\hline & married & $250(72)$ & $135.64 \pm 20.62$ & $\mathrm{~F}=0.71 * * *$ \\
\hline & divorced & $10(3)$ & $145.10 \pm 13.73$ & $P=0.55$ \\
\hline & widow & $3(1)$ & $137.67 \pm 61.65$ & \\
\hline \multirow{3}{*}{$\begin{array}{c}\text { Occupational } \\
\text { status }\end{array}$} & employed & $166(48)$ & $134.95 \pm 20.34$ & \multirow{3}{*}{$\begin{array}{c}\mathrm{F}=1.25^{* * *} \\
\mathrm{P}=0.29\end{array}$} \\
\hline & unemployed & 149 (49) & $136.77 \pm 22.64$ & \\
\hline & retired & $31(3)$ & $141.32 \pm 17.40$ & \\
\hline \multirow{3}{*}{ Occupation } & employee & $86(25)$ & $138.71 \pm 21.14$ & \multirow{3}{*}{$\begin{array}{l}\mathrm{F}=1.11^{* * *} \\
\mathrm{P}=0.332\end{array}$} \\
\hline & self-employed & $121(34)$ & $134.31 \pm 18.92$ & \\
\hline & housewife & $139(41)$ & $136.55 \pm 22.90$ & \\
\hline \multirow{4}{*}{ Education } & elementary school & $33(10)$ & $138.85 \pm 22.62$ & \multirow{4}{*}{$\begin{array}{c}\mathrm{F}=0.21^{* * *} \\
\mathrm{P}=0.89\end{array}$} \\
\hline & secondary school & $51(15)$ & $135.24 \pm 21.52$ & \\
\hline & diploma & $139(40)$ & $136.40 \pm 20.66$ & \\
\hline & academic & $123(35)$ & $135.95 \pm 21.36$ & \\
\hline \multirow{4}{*}{$\begin{array}{c}\text { Economic } \\
\text { status }\end{array}$} & very good & $13(4)$ & $138.38 \pm 23.00$ & \multirow{4}{*}{$\begin{array}{c}F=1.97^{* * *} \\
P=0.12\end{array}$} \\
\hline & good & $91(26)$ & $139.36 \pm 21.52$ & \\
\hline & medium & 204 (59) & $136.05 \pm 20.69$ & \\
\hline & weak & $38(11)$ & $129.61 \pm 21.27$ & \\
\hline \multirow{2}{*}{$\begin{array}{l}\text { History of } \\
\text { diabetes }\end{array}$} & Yes & $27(8)$ & $136.41 \pm 22.35$ & \multirow{2}{*}{$\begin{array}{l}T=0.03 * * \\
d f=30.05 \\
P=0.979\end{array}$} \\
\hline & No & $319(92)$ & $136.29 \pm 21.08$ & \\
\hline \multirow{2}{*}{$\begin{array}{c}\text { History of } \\
\text { hypertension }\end{array}$} & Yes & $35(10)$ & $134.17 \pm 23.67$ & \multirow{2}{*}{$\begin{array}{c}t=-0.63^{* *} \\
d f=344 \\
P=0.531\end{array}$} \\
\hline & No & $311(90)$ & $136.54 \pm 20.88$ & \\
\hline \multirow{2}{*}{$\begin{array}{l}\text { History of high } \\
\text { lipid serum }\end{array}$} & Yes & $54(16)$ & $138.74 \pm 23.28$ & \multirow{2}{*}{$\begin{array}{c}t=-0.63^{* *} \\
d f=344 \\
P=0.357\end{array}$} \\
\hline & No & $292(34)$ & $135.85 \pm 20.74$ & \\
\hline \multirow{3}{*}{$\begin{array}{l}\text { History of heart } \\
\text { disease }\end{array}$} & & & & \multirow{3}{*}{$\begin{array}{c}\mathrm{F}=1.60^{* * *} \\
\mathrm{P}=0.204\end{array}$} \\
\hline & Mother/father & $108(31)$ & $134.20 \pm 19.97$ & \\
\hline & Sister/brother & $9(3)$ & $146.11 \pm 15.06$ & \\
\hline \multirow{2}{*}{$\begin{array}{l}\text { History of } \\
\text { smoking }\end{array}$} & Yes & $39(11)$ & $133.90 \pm 20.34$ & \multirow{2}{*}{$\begin{array}{c}T=-0.75^{* *} \\
d f=344 \\
P=0.452\end{array}$} \\
\hline & No & 307 (89) & $136.61 \pm 21.26$ & \\
\hline \multirow{3}{*}{$\begin{array}{l}\text { History of alco- } \\
\text { hol consump- } \\
\text { tion }\end{array}$} & & & & \multirow{3}{*}{$\begin{array}{c}T=0.55^{* *} \\
d f=342 \\
P=0.584\end{array}$} \\
\hline & Yes & $16(5)$ & $139.25 \pm 20.70$ & \\
\hline & No & $328(95)$ & $136.28 \pm 21.16$ & \\
\hline
\end{tabular}

*Pearson's correlation coefficient; **Independent samples t-test; ***Analysis of variance 
Table 4. Multiple regression between knowledge of coronary heart disease and demographic variables

\begin{tabular}{|c|c|c|c|c|c|c|c|}
\hline \multirow[t]{2}{*}{ Variable } & \multicolumn{2}{|c|}{ Unstandardized Coefficients } & \multirow{2}{*}{$\begin{array}{l}\text { Standardized Co- } \\
\text { efficients (Beta) }\end{array}$} & \multirow[t]{2}{*}{$t$} & \multirow[t]{2}{*}{ Sig. } & \multicolumn{2}{|c|}{$\begin{array}{l}\text { Confidence Limit 95\% } \\
\text { for Regression Coef- } \\
\text { ficients (B) }\end{array}$} \\
\hline & SD & Coefficient & & & & $\begin{array}{l}\text { Upper } \\
\text { limit }\end{array}$ & Lower limit \\
\hline Constant Coefficient & 16.59 & 3.03 & - & 5.59 & $P<0.001$ & 10.98 & 22.92 \\
\hline Age, y & 0.07 & 0.02 & 0.19 & 2.92 & $P<0.001$ & 0.02 & 0.12 \\
\hline Marital status (single) & - & - & - & - & - & - & - \\
\hline $\begin{array}{l}\text { Marital status (mar- } \\
\text { ried) }\end{array}$ & 0.21 & 0.62 & 0.02 & 0.34 & 0.740 & -1.02 & 1.44 \\
\hline $\begin{array}{l}\text { Marital status (di- } \\
\text { vorced) }\end{array}$ & -3.85 & 1.5 & -0.14 & -2.57 & 0.040 & -6.8 & -0.9 \\
\hline Marital status (widow) & -1.39 & 2.61 & -0.03 & -0.53 & 0.590 & -6.53 & 3.74 \\
\hline $\begin{array}{l}\text { Occupational status } \\
\text { (unemployed) }\end{array}$ & - & - & - & - & - & - & - \\
\hline $\begin{array}{l}\text { Occupational status } \\
\text { (employed) }\end{array}$ & 0.11 & 0.5 & 0.01 & 0.22 & 0.820 & -0.87 & 1.09 \\
\hline $\begin{array}{l}\text { Occupational status } \\
\text { (retired) }\end{array}$ & 0.43 & 0.95 & 0.03 & 0.45 & 0.650 & -1.44 & 2.3 \\
\hline Financial status & -0.88 & 0.34 & -0.13 & -2.57 & 0.010 & -1.22 & -0.21 \\
\hline History of diabetes & -0.29 & 0.96 & -0.02 & -0.3 & 0.760 & -2.17 & 1.59 \\
\hline $\begin{array}{l}\text { History of high lipid } \\
\text { serum }\end{array}$ & -1.44 & 0.72 & -0.12 & -2.01 & 0.040 & -2.85 & -0.03 \\
\hline $\begin{array}{l}\text { History of alcohol } \\
\text { consumption }\end{array}$ & 1.26 & 0.94 & 0.07 & 1.35 & 0.180 & -0.58 & 3.1 \\
\hline
\end{tabular}

Client- Centered Nursing Care

to the dimensions of spiritual growth and interpersonal relationship (Abedi, Shafiee \& Ghoddosi, 2014). Health promoting behaviors, such as balanced nutrition, physical activity, weight control, and stress management, are the basis for preventing cardiovascular disease; they reduce up to $90 \%$ of heart disease occurrence rates. These modifiable risk factors can be managed by a healthy lifestyle (Chinekesh et al. 2018).

Using multiple regression model, in this research and after controlling conflicting variables (age, weight, occupation and economic status), there was a significant relationship between knowledge on coronary heart disease risk factors and a health-promoting lifestyle. A cohort study reported that knowledge of coronary heart disease risk factors positively affects people's lifestyle (Åkesson et al. 2014). A study titled: “Association between Lifestyle-related Risk Factors and Coronary Artery Disease" indicated that the main lifestyle risk fac- tors for coronary artery disease were inadequate fruit consumption, the excessive consumption of eggs, and the level of daily smoking (Amiri et al. 2016).

Another study also indicated a positive correlation between awareness about coronary heart disease risk factors and health-promoting behaviors (Ammouri et al. 2018). Other studies have indicated that awareness of cardiovascular risk factors does not correlate with a healthy lifestyle (Johnson et al. 2015; Mullie \& Clarys2011).

The obtained data revealed that people's knowledge on coronary heart disease risk factors is associated with variables, such as age, marital status, occupation, economic status, as well as histories of high serum lipid and alcohol consumption. 
According to prior research, marital status, education, and age are the best predictors of awareness on heart disease risk factors (Angosta \& Speck, 2014). In another study, high income, higher education, and female gender mainly influenced the awareness of people about heart disease risk factors (Wagner et al. 2005). Other studies have indicated that men with higher levels of awareness had lower levels of triglyceride (Burger et al. 2016).

A study evaluated variables such as gender, age, smoking status, systolic blood pressure and HDL cholesterol in relation to cardiovascular disease; they reported these factors were effective in increasing odds ratio for vascular occlusion (Bidel et al. 2015).

Moreover, the obtained results of regression analysis suggested that age, weight, occupation, economic status, and individual's knowledge on coronary heart disease risk factors have separately affected the health-promoting lifestyle in level 0.2. A study reported that age, gender, and occupation influence a health-promoting lifestyle. A health-promoting lifestyle mean score in people with a history of hypertension, cholesterol, heart disease, cigarette smoking, and alcohol consumption was not significantly different from those without these risk factors (Mousavian 2014). Another study indicated a significant relationship between type 2 diabetes mellitus and a health-promoting lifestyle (Angosta \& Speck 2014).

Performing educational interventions at different levels of prevention are suggested for a health-promoting lifestyle among patients with coronary heart disease. The importance of physical activity in the prevention of coronary artery disease should be emphasized in such courses. Considering the importance of awareness of risk factors and a health-promoting lifestyle as the first step in the prevention of coronary artery disease, and regarding the key role of nurses in educating patients to promote their health, the results of this research can provide a basis for a greater understanding of the importance of lifestyle and strengthening healthy behaviors in reducing risk factors in nursing education and services.

\section{Ethical Considerations}

\section{Compliance with ethical guidelines}

After obtaining permission from the Ethics Committee of Iran University of Medical Sciences (Code of ethics: IR.IUMS.REC.1396.9511690002), the purpose of the study was initially explained to the study participants, written consent was obtained from them, and the study participants were confirmed about the confidentiality of their information.

\section{Funding}

This research was extracted from the MSc. thesis of the second author, Department of Department of Community Health, School of Nursing and Midwifery, Iran University of Medical Sciences.

\section{Authors' contributions}

Conceptualization: Sakineh Tarvirdinasab, Marhamat Farahaninia, Zahra Ahmadi; Methodology: Sakineh Tarvirdinasab, Marhamat Farahaninia and Hamid Haghani; Investigation: Sakineh Tarvirdinasab; Writing original draft, Writing-review and editing: Sakineh Tarvirdinasab, Marhamat Farahaninia; and Supervision: Marhamat Farahaninia.

\section{Conflict of interest}

The authors declare no conflicts of interests.

\section{Acknowledgments}

We sincerely thank of Faculty of Nursing and Midwifery, and all those involved in the study are also appreciated.

\section{References}

Abedi, H. A., Shafiee, A. \& Ghoddosi, A., 2014. Evaluation of health promotion activities in diabetic patients type II admitted to clinics in Najaf Abad 2013. Jundishapur Journal of Chronic Disease Care, 3(2), pp. 25-35.

Åkesson, A., et al., 2014. Low-risk diet and lifestyle habits in the primary prevention of myocardial infarction in men: A population-based prospective cohort study. Journal of the American College of Cardiology, 64(13), pp. 1299-306. [DOI:10.1016/j. jacc.2014.06.1190] [PMID]

Amiri, F., et al., 2016. The association between lifestyle-related risk factors and coronary artery disease in residents of Yazd province: A case-control study. Journal of Health and Development, 5(2), pp. 98-109.

Ammouri, A. A., et al., 2018. Risk knowledge and awareness of coronary heart disease, and health promotion behaviors among adults in Oman. Research and Theory for Nursing Practice, 32(1), pp. 46-62. [DOI:10.1891/0000-000Y.32.1.46] [PMID]

Anderson, L., et al., 2016. Exercise-based cardiac rehabilitation for coronary heart disease: Cochrane systematic review and meta-analysis. Journal of the American College of Cardiology, 67(1), pp. 1-12. [DOI:10.1016/j.jacc.2015.10.044] [PMID] 
Angosta, A. D. \& Speck, K. E., 2014. Assessment of heart disease knowledge and risk factors among first-generation Filipino Americans residing in Southern Nevada: A cross-sectional survey. Clinical Nursing Studies, 2(2), pp. 123-9. [DOI:10.5430/ cns.v2n2p123]

Baldwin, S. A. S., 2014. Coronary heart disease knowledge, health promoting behaviors and perceived benefits and barriers to exercise and healthy eating in Montana females [PhD. dissertation]. Bozeman: Montana State University.

Bhandari, P. \& Kim, M., 2016. Predictors of the health-promoting behaviors of Nepalese migrant workers. Journal of Nursing Research, 24(3), pp. 232-9. [DOI:10.1097/jnr.0000000000000120] [PMID]

Bidel, Z., et al., 2015. Association of cardiovascular risk factors and coronary arteries involvement based on angiographic. Findings Journal of Ilam of Medical Sciences, 22(1), pp. 147-54 [DOI:10.17795/jbm-5346]

Burger, A., et al., 2016. The relationship between cardiovascular risk factors and knowledge of cardiovascular disease in African men in the North-West Province. Health Sa Gesondheid, 21(1), pp. 364-71. [DOI:10.1016/j.hsag.2016.07.003]

Capewell, S., et al., 2009. Modelling the UK burden of cardiovascular disease to 2020. London: Cardio \& Vascular Coalition and the British Heart Foundation.

Carr, H. J., et al., 2013. The effectiveness of computer-based learning in hospitalized adults with heart failure on knowledge, readmission, self-care, quality of life, and patient satisfaction: A systematic review protocol. JBI Database of Systematic Reviews and Implementation Reports, 11(8), pp. 129-45. [DOI:10.11124/ jbisrir-2014-1430]

Chinekesh, A., et al., 2018. A comprehensive health plan: The lifestyle affecting factors in iranian youth. International Journal of Preventive Medicine, 9(1), pp. 1-8. [DOI:10.4103/ijpvm. IJPVM_309_17] [PMID] [PMCID]

Chiou, A. F., Hsu, S. P. \& Hung, H. F., 2016. Predictors of health-promoting behaviors in Taiwanese patients with coronary artery disease. Applied Nursing Research, 30, pp. 1-6. [DOI:10.1016/j.apnr.2015.08.008] [PMID]

Hajizadeh-Sharafabad, F., and Alizadeh, M., 2016. Predictors Of Health-Promoting Behaviors In Patients With Coronary Artery Disease In The Iranian Population. International Journal of Nursing Practice, 22(5), pp. 486-92. [DOI:10.1111/ijn.12459] [PMID]

Chiuve, S. E., et al., 2008. Primary prevention of stroke by healthy lifestyle. Circulation, 118(9), pp. 947-54. [DOI:10.1161/ CIRCULATIONAHA.108.781062] [PMID] [PMCID]

Cho, J. H., et al., 2014. Health-promoting behaviour among women with abdominal obesity: A conceptual link to social support and perceived stress. Journal of Advanced Nursing, 70(6), pp.1381-90. [DOI:10.1111/jan.12300] [PMID]

Dawber, T. R., Moore, F. E. \& Mann, G. V., 2015. II. Coronary heart disease in the Framingham study. International Journal of Epidemiology, 44(6), pp. 1767-80. [DOI:10.1093/ije/dyv346] [PMID]

de Melo Ghisi, G. L., et al., 2014. A systematic review of patient education in cardiac patients: Do they increase knowledge and promote health behavior change? Patient Education and
Counseling, 95(2), pp.160-74. [DOI:10.1016/j.pec.2014.01.012] [PMID]

Forouzanfar, M. H., et al., 2014. Evaluating causes of death and morbidity in Iran, global burden of diseases, injuries, and risk factors study 2010. Archives of Iranian Medicine, 17(5), p. 304-20. [DOI:0141705/AIM.004] [PMID]

Ghaffari, S., et al., 2017. Is female gender associated with worse outcome after ST elevation myocardial infarction? Indian Heart Journal, 69(Suppl. 1), pp. S28-S33. [DOI:10.1016/j. ihj.2016.12.003] [PMID] [PMCID]

Hu ghes, J., et al., 2015. Modelling future coronary heart disease mortality to 2030 in the British Isles. PLOS One, 10(9), p. e0138044. [DOI:10.1371/journal.pone.0138044] [PMID] [PMCID]

Johnson, J. E., et al., 2015. Does knowledge of coronary artery calcium affect cardiovascular risk perception, likelihood of taking action, and health-promoting behavior change? Journal of Cardiovascular Nursing, 30(1), pp.15-25. [DOI:10.1097/ JCN.0000000000000103] [PMID]

Mahmoodi, G., et al., 2014. A study of health-promoting behaviors of medical sciences students of Islamic Azad University of Sari, Iran 2013. Iranian Journal of Health Sciences, 2(2), pp. 52-7. [DOI:10.18869/acadpub.jhs.2.2.52]

Mohammadi Zeidi, I., Pakpour Hajiagha, A. \& Mohammadi Zeidi, B., 2012. [Reliability and validity of Persian version of the health-promoting lifestyle profile (Persian)]. Journal of Mazandaran University of Medical Sciences, 21(1), pp. 102-13.

Mohammadian-Hafshejani, A., et al., 2014. Seasonal pattern in admissions and mortality from acute myocardial infarction in elderly patients in Isfahan, Iran. ARYA Atherosclerosis, 10(1), pp. 46-54. [PMID] [PMCID]

Mohsenipoua, H., et al., 2016. Predictors of health-promoting behaviors in coronary artery bypass surgery patients: An application of Pender's health promotion model. Iranian Red Crescent Medical Journal, 18(9), p. e38871. [DOI:10.5812/ircmj.38871] [PMID] [PMCID]

Mousavian, M., 2014. Health promoting behaviors among adolescents: A cross-sectional study. Nursing and Midwifery Studies, 3(1), pp. e14560-65. [DOI:10.17795/nmsjournal14560]

Mullie, P. \& Clarys, P., 2011. Association between cardiovascular disease risk factor knowledge and lifestyle. Food and Nutrition Sciences, 2(10), p. 1048. [DOI:10.4236/fns.2011.210140]

Najafi, G. T., Kassaye, T. M. \& Emami, A., 2015. Sex differences and symptoms of acute coronary syndrome. Journal of Clientcentered Nursing Care, 1(3), pp. 119-24.

Pouy, H., 2015. [Relationship between health promoting behaviors and severityof coronary artery stenosis in angiography department in Mazandaran Heart Center (Persian)]. Journal of Mazandaran University of Medical Sciences, 25(130), pp. 19-29.

Qidwai, W. \& Ashfaq, T., 2013. Role of garlic usage in cardiovascular disease prevention: An evidence-based approach. Evidence-Based Complementary and Alternative Medicine, 2013, p. 125649. [DOI:10.1155/2013/125649] [PMID] [PMCID]

Shaheen, A. M., et al., 2015. Factors affecting health-promoting behaviors of university students in Jordan. Health, 7(01), pp. 1-8. [DOI:10.4236/health.2015.71001] 
Varbo, A., et al., 2013. Remnant cholesterol as a causal risk factor for ischemic heart disease. Journal of the American College of Cardiology, 61(4), pp. 427-36. [DOI:10.1016/j.jacc.2012.08.1026] [PMID]

Wagner, J., et al., 2005. Development of a questionnaire to measure heart disease risk knowledge in people with diabetes: The heart disease fact questionnaire. Patient Education and Counseling, 58(1), pp. 82-7. [DOI:10.1016/j.pec.2004.07.004] [PMID]

Walker, S. N., Sechrist, K. R. \& Pender, N. J., 1987. The healthpromoting lifestyle profile: Development and psychometric characteristics. Nursing Research, 36(2), pp. 76-81. [DOI:10.1097/00006199-198703000-00002]

Yusuf, S., et al., 2015. The World Heart Federation's vision for worldwide cardiovascular disease prevention. The Lancet, 386(9991), pp. 399-402. [DOI:10.1016/S0140-6736(15)60265-3] 